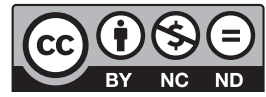

Estudos Teológicos foi licenciado com uma Licença Creative Commons Atribuição - NãoComercial - SemDerivados 3.0 Não Adaptada

http://dx.doi.org/10.22351/et.v59i1.3315

\title{
O Espírito Santo Na tradição PROTESTANTE: PERSPECTIVAS A PARTIR DA TEOLOGIA REFORMADA ${ }^{1}$
}

\author{
The Holy Spirit in the Protestant tradition: \\ Reformed theological perspectives
}

\section{Carlos Ribeiro Caldas Filho}

Resumo: A teologia cristã tem dedicado muito espaço e atenção para a reflexão a respeito do ser de Deus - teologia propriamente - e da pessoa de Cristo - cristologia. Mas nem sempre tem sido dada atenção ao Espírito Santo, a "pessoa esquecida da Trindade". O presente artigo apresenta, ainda que apenas em síntese, como a vertente da Reforma Protestante do século XVI, conhecida popular, mas erroneamente, como "calvinista", elaborou o tema pneumatológico, isto é, a doutrina da pessoa e da obra do Espírito Santo. Para tanto, recorrerá à sua principal fonte primária, a saber, textos de João Calvino, e a dois teólogos reformados contemporâneos, quais sejam, Hendrikus Berkhof e Jürgen Moltmann. Palavras-chave: Espírito Santo. Pneumatologia. João Calvino. Hendrikus Berkhof. Jürgen Moltmann.

Abstract: Christian theology has given too much room and attention to the reflection about the being of God - theology itself - and to the person of Christ - Christology. However, not always too much attention has been given to the Holy Spirit, "the forgotten person of the Trinity". This text deals with the question of how the branch of the Protestant Reformation of the $16^{\text {th }}$ century, known popularly, but mistakenly, as "Calvinist", elaborated the pneumatological theme. To do so, it will work with its main primary source, that is, John Calvin's writings, and also with two contemporary Reformed theologians, namely, Hendrikus Berkhof and Jürgen Moltmann.

Keywords: Holy Spirit. Pneumatology. John Calvin. Hendrikus Berkhof. Jürgen Moltmann.

1 O artigo foi recebido em 10 de maio de 2018 e aprovado em 02 de outubro de 2018 com base nas avaliações dos pareceristas ad hoc.

Este texto é a adaptação da apresentação feita pelo autor no Painel Teológico "Perspectivas pneumatológicas: o Espírito Santo nas tradições católica e protestante", acontecido na Faculdade Jesuíta de Filosofia e Teologia em 03 de maio de 2017. Os outros dois participantes foram o Prof. Dr. Manoel Hurtado, SJ, (Universidad Católica de Bolívia, em Cochabamba, e FAJE), e o Prof. Dr. Wilhelm Wachholz (Faculdades EST, de São Leopoldo/RS). O autor é grato à organização do evento pelo convite que lhe foi feito para apresentação de trabalho no mesmo.

2 Doutor em Ciências da Religião pela Universidade Metodista de São Paulo (UMESP), com pós-doutorado na Faculdade Jesuíta de Filosofia e Teologia (FAJE). Professor na Pontifícia Universidade Católica de Minas Gerais (PUC Minas) em Belo Horizonte, Minas Gerais. Contato: crcaldas2009@hotmail.com 


\section{Introdução - A Trindade como o grande diferencial da fé cristã}

Credo in Spiritum Sanctum - Creio no Espírito Santo. Simples assim. Essa é a afirmação do Credo Apostólico, o primeiro símbolo da fé cristã, quanto ao Espírito Santo, terceira pessoa da Santíssima Trindade. Já o Credo Niceno-Constantinopolitano ${ }^{3}$ tem uma afirmação mais elaborada: "Cremos... no Espírito Santo, Senhor e Fonte da vida, que procede do $\mathrm{Pai}^{4}$; e com o Pai e o Filho é adorado e glorificado. Ele falou pelos profetas"s.

Vê-se que o cristianismo, desde seus primórdios, em suas duas vertentes geográfico-culturais, quais sejam, a oriental grega e a ocidental latina, tem fé trinitária: Deus é Pai, Deus é Filho, Deus é Espírito Santo. A igreja medieval, de igual maneira, no Oriente e no Ocidente, sustenta essa mesma fé. Evidências eloquentes dessa fé encontram-se em hinos como Veni Creator Spiritus, do século IX. Embora a ênfase desse hino seja pneumatológica, o acento trinitário é nitidamente subjacente:

Vinde Espírito Criador, a nossa alma visitai e enchei os corações com vossos dons celestiais.

Vós sois chamados o Intercessor de Deus, excelso dom sem par,

a fonte viva, o fogo, o amor, a unção divina e salutar.

Sois o doador dos sete dons e sois poder na mão do Pai,

por Ele prometido a nós, por nós seus feitos proclamai.

A nossa mente iluminai, os corações enchei de amor,

nossa fraqueza encorajai, qual força eterna e protetor.

Nosso inimigo repeli, e concedei-nos a vossa paz,

se pela graça nos guiais, o mal deixamos para trás.

Ao Pai e ao Filho Salvador, por vós possamos conhecer

que procedeis do Seu amor, fazei-nos sempre firmes crer.

Amém! ${ }^{6}$

3 O Credo Niceno-Constantinopolitano é uma declaração ou símbolo de fé aceito pelas igrejas ortodoxas orientais, católica romana, anglicana e protestantes tradicionais. Trata-se de uma modificação feita pelo Concílio de Calcedônia (451) do Credo Niceno (325), o que gerou a expressão "Niceno-Constantinopolitano".

4 Não se entrará na discussão da "cláusula Filioque", adendo das igrejas latinas ao texto do Credo Niceno-Constantinopolitano, motivo de grande controvérsia entre as igrejas ocidentais e orientais, a respeito da procedência do Espírito Santo. Para as igrejas orientais de expressão grega, o Espírito "procede do Pai”, enquanto que nas ocidentais de expressão latina, por conta desse adendo, o Espírito procede do Pai "e do Filho". A falta de acordo quanto ao Filioque levou à cisão entre os ramos oriental grego e ocidental latino do cristianismo em 1054.

5 Apud BETtENSON, Harry. Documentos da igreja cristã. São Paulo: ASTE, 1967. p. 56.

6 VENI CREATOR SPIRITUS. Oração ao Espírito Santo. Disponível em: <http://www.comshalom.org/ oracao-ao-espirito-santo-veni-creator-spiritus/>. Acesso em: 21 abr. 2017. 
E Veni Sancte Spiritus, datado provavelmente do início do século XIII:

Veni, Sancte Spiritus

Vinde, Espírito Santo

Et emitte caelitus

enviai dos céus

lucis tuae radium!

um raio de luz!

Veni, pater pauperum

Vinde, Pai dos pobres

veni, dator munerum

vinde, doador de dons

veni, lumen cordium.

vinde, luz dos corações.

Consolator optime

Consolo que acalma

Dulcis hospes animae

doce hóspede da alma

dulce refrigerium.

doce alívio.

In labore requies

No labor descanso

In aestu temperies

na aflição remanso

in fletu solatium.

no calor aragem.

O lux beatissima

Enchei, luz beatíssima

reple cordis intima

chama que crepita

tuorum fidelium.

o íntimo de nós.

Sine tuo numine

Sem a tua luz

nihil est in homine

nada o homem pode

nihil est innoxium.

nenhum bem há nele.

Lava quod est sordidum

lava o que é sujo

riga quod est aridum

rega o que é árido

sana quod est saucium.

curai o doente.

Flecte quod est rigidum 
Dobrai o que é duro

fove quod est frigidum

aquece o que é frio

rege quod est devium.

abre caminho nas trevas.

Da tuis fidelibus

Dá aos teus fiéis

in te confidentibus

que confiam em ti

sacrum septenarium.

teus sete dons.

Da virtutis meritum

dai em prêmio da virtude

da salutis exitum

uma santa morte

da perenne gaudium.

alegria eterna.

Amen, Alleluia.

Amém, aleluia ${ }^{7}$.

Não é demais repetir: a fé cristã, desde seus primórdios, é trinitária. Esse é o diferencial do cristianismo em relação aos demais credos monoteístas (judaísmo e islamismo) e, de resto, em relação a todos os demais credos, politeístas e/ou não teístas. Todavia, a reflexão sobre a fé, isto é, a teologia, tem, em geral, cometido uma incoerência, que se constitui em quase contradição: um virtual esquecimento da pessoa e da obra do Espírito Santo, a ponto tal de alguém ter afirmado que o Espírito Santo é a "Cinderela da teologia": o Pai e o Filho estão em destaque, enquanto a terceira pessoa da Trindade praticamente cai no olvido. Tal situação talvez seja explicada pelo fato de que, conscientemente ou não, as lideranças eclesiásticas e os círculos de reflexão teológica tenham medo da imprevisibilidade e da liberdade absoluta do Espírito, descrito como vento que sopra onde, como e quando quer, e não pode ser controlado, nem guiado ou manipulado (cf. Jo 3.8). Isso foi dramaticamente desafiado no início do século passado com o surgimento do pentecostalismo moderno. Desde então, na maioria das vezes por motivação apologética, muitas pneumatologias foram escritas - curioso pensar que foi preciso uma "provocação", por assim dizer, do movimento pentecostal para que teólogos protestantes e católicos tradicionais se lembrassem do tema pneumatológico em suas elaborações teológicas.

\footnotetext{
7 VENI SANCTE SPIRITUS. Disponível em: < https://sumateologica.wordpress.com/2010/04/27/veni-
} sancte-spiritus-com-traducao/>. Acesso em: 21 abr. 2017. 


\section{Movimentos do Espírito na tradição protestante}

Neste sentido, chega a ser uma ironia que a teologia protestante clássica, a teologia da reforma magisterial (luterana e reformada) tenha praticamente se esquecido da reflexão pneumatológica. Isso porque a história do protestantismo, em suas várias ramificações, é marcada por movimentos de irrupção da presença e da dinâmica do Espírito de maneira muito intensa. Exemplos: o Primeiro Grande Avivamento (First Great Awakening) ${ }^{8}$, acontecido na década de 1730 nos dois lados do Atlântico Norte, de inspiração teológica calvinista, tendo como principais líderes, no lado dos Estados Unidos, Jonathan Edwards (1703-1758) ${ }^{9}$, e no lado do Reino Unido, George Whitefield.

Não muito depois, tem lugar o Segundo Grande Avivamento (Second Great Awakening), esse acontecido apenas nos Estados Unidos, no início do século XIX, tendo como um de seus principais nomes o advogado Charles Finney. O Segundo Grande Avivamento é particularmente interessante porque gerou influências que tiveram posteriores consequências importantes na história dos movimentos do Espírito na tradição protestante. Dentre esses, merecem ser citados dois, que terão implicação direta na grande "explosão" do Espírito no século XX, com repercussões até os nossos dias, que certamente ainda se farão sentir por muito tempo: um, os movimentos de santidade (Holiness), de influência wesleyana, e o outro, os movimentos das igrejas evangélicas negras (Black Evangelicals $)^{10}$.

Afirmou-se acima que dois movimentos em particular, ambos derivados do Segundo Grande Avivamento - os movimentos de santidade e o movimento das igrejas evangélicas negras - são particularmente importantes para entender a explosão pentecostal do século XX. Pois foi em uma igreja de negros na rua Azusa (Azusa Street) em Los Angeles, a Igreja Metodista Episcopal Afro-Americana (com nítidas influências wesleyanas Holiness), que em 14 de abril de $1906^{11}$, sob a liderança de William Joseph Seymour, filho de ex-escravos, em um culto, iniciou-se um movimento de glossolalia (o falar em outras línguas ou "línguas estranhas") e manifestações extáticas absolutamente incomuns, além de uma espontaneidade nos cultos que chocava e escandalizava o padrão dominante das demais igrejas. Esses movimentos logo chamaram a atenção da imprensa estadunidense, não demorando a que o pentecostalismo se

8 Para detalhes, consultar, inter alia, KIDD, Thomas. The Great Awakening: Evangelical Roots of Christianity in America. Yale: Yale University Press, 2007.

9 Jonathan Edwards é figura indispensável para se entender o protestantismo dos Estados Unidos: era da Igreja Congregacional, que tem origem nos movimentos separatistas ingleses do século XVII, e calvinista em termos doutrinários. Foi missionário junto a alguns grupos de povos indígenas da região da Costa Leste de seu país. Ao mesmo tempo, era um filósofo iluminista. Para detalhes, consultar, inter alia, EDWARDS, Jonathan. A verdadeira obra do Espírito. Sinais de autenticidade. São Paulo: Vida Nova, 1992.

${ }_{10}$ Para detalhes quanto ao Segundo Grande Avivamento, consultar, inter alia, MARSDEN, George. The Evangelical Mind and the New School Presbyterian Experience: A Case Study of Thought and Theology in Nineteenth-Century America. Eugene: Wipf \& Stock, 2003.

${ }^{11}$ Conquanto haja notícias de fenômenos semelhantes aos da rua Azusa acontecidos antes de 1906, entre cristãos armênios, a data 14 de abril de 1906 é praticamente consensual entre os historiadores como sendo a do início do pentecostalismo. 
espalhasse como fogo em mato seco, e fenômenos semelhantes não tardaram a acontecer em igrejas de membresia "WASP" (White, Anglo-Saxon, Protestant, "branco, anglo-saxão, protestante", a definição clássica do cidadão estadunidense mediano). Pouco mais de cem anos desde então, o pentecostalismo corresponde a cerca de um quarto do total da população cristã no planeta. ${ }^{12}$

\section{O lugar do Espírito Santo na tradição da teologia reformada - a pneumatologia cristológico-salvífica de Calvino}

Todavia, o foco do presente artigo não é nem tanto a história dos movimentos do Espírito na tradição protestante, mas a compreensão teológica desenvolvida pelo protestantismo de linha reformada da pessoa e da obra do Espírito. Pois já em João Calvino (1509-1564) a teologia do Espírito tem grande valor e importância. ${ }^{13}$ Portanto o teólogo presbiteriano norte-americano Benjamin Warfield disse:

Assim como se pode dizer que a doutrina do pecado e da graça vem de Agostinho, a doutrina da satisfação, de Anselmo, a doutrina da justificação pela fé, de Lutero, devemos dizer que a doutrina da obra do Espírito Santo é um presente de Calvino à igreja ${ }^{14}$.

De fato, nas Institutas, Calvino dará lugar de destaque ao Espírito. ${ }^{15}$ Neste sentido, Calvino inicia o que pode ser considerado uma pneumatologia protestante in

12 Dados extraídos de PEW RESEARCH CENTER - RELIGION AND PUBLIC LIFE. Global Christianity - A Report on the Size and Distribution of World's Christian Population. Disponível em: <http://www. pewforum.org/2011/12/19/global-christianity-exec/>. Acesso em: 14 jun. 2017.

13 Entretanto, há que se lembrar que nem Calvino nem nenhum de seus contemporâneos produziu uma pneumatologia sistemática. Isso só aconteceria no século seguinte, já no período pós-Reforma, com o puritano inglês John Owen em sua obra Pneumatalogia, or, A Discourse Concerning the Holy Spirit, publicado originalmente em 1674. Dentre os teólogos reformados posteriores que produziram pneumatologias sistemáticas podem ser citados: James Buchanan, The Office and Work of the Holy Spirit, publicado originalmente em 1847; Octavius Winslow, An Experimental and Practical View of the Work of the Holy Spirit, publicado originalmente em 1843; George Smeaton, The Doctrine of the Holy Spirit, publicado originalmente em 1882, e a alentada obra de Abraham Kuyper, considerado o pai do neocalvinismo holandês, The Work of the Holy Spirit, publicada originalmente em holandês em 1888, e em inglês em 1900, tendo sido republicada em inglês em 1956.

14 WARFIELD, B. B. Calvin and Augustine. Philipsburg: Presbyterian and Reformed, 1956. p. 484. (tradução nossa).

15 Há uma pletora de estudos sobre a compreensão de Calvino quanto à pessoa e à obra do Espírito. Uma lista, sugestiva apenas, inclui: ABEL, Jean. The ethical implications of the doctrine of the Holy Spirit in John Calvin. 1948. Master Thesis (Theology) - Union Theological Seminary, Richmond, 1948. BEINTKER, Michael. Calvins Theologie des Heiligen Geistes. Disponível em: < http://www.reformiert-info.de/daten/ File/Upload/doc-2435-1.pdf>. Acesso em: 23 abr. 2017. BENNETT, Charles Oliver. John Calvin: his teaching on the Holy Scriptures: a study on the necessity of the Scriptures in the Holy Spirit's effectual call of the saints. 1951. Master Thesis (Theology) - New Brunswick Theological Seminary, New Brunswick, 1951. MORII, Makoto. La notion du Saint-Esprit chez Calvin dans son development historique. 1961. Thése de maîtrise (Théologie) - Faculté de Théologie Protestante de Strasbourg, Strasbourg, 1961. O'BRIEN, Henry. The Holy Spirit in the catechetical writings of John Calvin: a comparative study with other contemporary presentations of Christian doctrine between 1529 and 1566. 1991. Doctoral 
nuce, com contornos que diferenciarão da compreensão católica: se nesta a igreja e a mediação sacerdotal ocupam lugar de destaque para que aconteça a experiência da salvação, Calvino deslocará esse lugar de destaque para a atuação do Espírito na vida da pessoa: "Sem a iluminação do Espírito Santo, a Palavra de Deus nada faz" e "não podemos ir a Cristo, a não ser que sejamos trazidos pelo Espírito de Deus". ${ }^{16}$ Neste mesmo contexto, Calvino afirma:

A Palavra de Deus foi apreendida pela fé; ao contrário, tê-lo-á sido quando deitou raízes no íntimo do coração, de sorte que seja um baluarte invencível para suster e repelir a todos os engenhos das tentações. Pois que, se é verdadeiro que a real compreensão da mente é a Sua iluminação, em tal confirmação do coração muito mais evidente Lhe transparece o poder, isto é, em que não só maior é a desconfiança do coração que a cegueira da mente, mas também mais difícil é prover-se o ânimo de certeza que do conhecimento imbuir-se a mente. Consequentemente, o Espírito faz as vezes de um selo para marcar-nos no coração estas próprias promessas cuja certeza antes imprimiu-nos à mente e toma Ele o lugar de um penhor para confirmá-las e estabelecê-las ${ }^{17}$.

Essa é uma ideia que Calvino extraiu de Lutero, que, em seu Catecismo Maior, de 1529, ao comentar sobre o Credo Apostólico, dissera que é o Espírito que nos conduz à igreja, à comunhão dos santos. Calvino amplia e desenvolve esse insight teológico de Lutero. Na teologia protestante, então, conforme primeiramente entendido por Lutero, e depois expandido por Calvino, a igreja é importante, mas nunca como um fim em si - a igreja só existe pela obra do Espírito Santo. Em outras palavras: o Espírito Santo é a origem, a causa da igreja. Talvez aí se encontre a raiz da eclesiologia "baixa" protestante. A importância da igreja enquanto instituição é minimizada e relativizada diante da obra do Espírito Santo. Porque ao dar lugar de destaque ao Espírito Santo no processo de iluminação para a leitura bíblica, e da aplicação da salvação, a pneumatologia protestante, esboçada por Lutero, desenvolvida por Bucer e ampliada por Calvino, tira a importância do magistério da igreja. É o Espírito, atuando na mente e no coração do indivíduo, que faz com que a Bíblia seja entendida e que a experiência da salvação aconteça. Daí vem a expressão de Calvino que se tornou

dissertation (Theology) - Pontificia Universitas Gregoriana, Facultas Theologiae, Vaticano, 1991. QUISTORP, Heinrich J. J. Th. Calvins Lehre vom Heiligen Geist. In: VRIEZEN Theodorus Christiaan, De Spiritu Sancto. Bijdragen tot de leer van de Heilige Geest bij gelegenheid van het 2e eeuwfeest van het Stipendium Bernardinum. Utrecht: Kemifik, 1964. p. 109-150; VAN‘T SPIJKER, W. Die Lehre vom Heiligen Geist bei Bucer und Calvin. In: NEUSER, Wilhem H. (Ed.). Calvinus Servus Christi. Die Referate des Internationalen Kongresses für Calvinforschung, Debrecen, 1986. Debrecen, 1986. Budapest: Presseabteilung des Raday-Kollegiums, 1988. p. 73-106; WALTERS, Gwyn. The Doctrine of the Holy Spirit in John Calvin. 1949. Ph. D. Thesis (Theology) - University of Edinburgh, Edinburgh, 1949. ZERWAS, Jack La-Vere. The Holy Spirit in Calvin. 1947. Master Thesis (Theology) - Union Theological Seminary, New York, 1947.

${ }^{16}$ CALVINO, Institutas, III.2.33-34. São Paulo: Casa Editora Presbiteriana; Campinas: Luz para o Caminho, 1989. p. 43-45.

${ }^{17}$ CALVINO, Institutas, III.2.36, p. 46. 
famosa: testimonium Spiritus Sancti internum (Institutas I.7), o "testemunho interno do Espírito Santo"18.

Calvino desenvolve uma soteriologia que é, ao mesmo tempo, pneumatológica e cristológica: "para que o derramar do seu (i.e., de Cristo) sangue sagrado não seja anulado, nossas almas precisam ser purificadas pelo lavar secreto do Espírito"19. Em seu comentário de João 6.65 ("E prosseguiu: por causa disto é que vos tenho dito: ninguém poderá vir a mim, se, pelo Pai, não lhe for concedido" ${ }^{20}$, isso vos disse que ninguém pode vir a mim se não lhe for concedido pelo Pai”), Calvino afirmará que, em verdade, "a fé procede apenas da revelação secreta do Espírito"21. Calvino deixa claro que compreende a ação do Espírito Santo como já existente nos tempos da antiga aliança, ou seja, o Espírito não é uma "novidade" inaugurada apenas no dia de Pentecostes (cf. At 2). Comentando Êxodo 30.23-25 (que contém as instruções para o preparo do óleo aromático sagrado da unção sacerdotal), Calvino afirmou: "o tabernáculo foi aspergido com óleo para que os israelitas pudessem aprender que todos os exercícios de piedade não são de proveito algum sem a operação secreta do Espírito"22. Tal é a importância do Espírito na teologia de Calvino, que o estudioso francês François Wendell resumiu com admirável precisão e acerto quando disse que "Calvino nunca se cansa de dizer que o Espírito Santo é o vínculo pelo qual o Filho de Deus nos une efetivamente a Ele (= ao Filho)" ${ }^{\prime 23}$. Resumindo: em Calvino há um vínculo indissociável entre o salvo, a Palavra e Cristo, sendo que esse vínculo é o Espírito. Calvino compreende que é exatamente a ação do Espírito que procede a unio mystica, isto é, a união mística do salvo com Cristo. ${ }^{24}$ Essa união é vivencial e dinâmica, não especulativa e estática. A vida cristã para Calvino é a união mística com Cristo. ${ }^{25} \mathrm{O}$ testemunho interno do Espírito Santo dá ao cristão a segurança de viver um relacionamento com Deus na perspectiva da união mística com Cristo, o que lhe (i.e., ao cristão) concede coragem, esperança, alegria, força e paz, e o capacita para, na companhia dos demais

18 O tema do testimonium Spiritus Sancti internum aparecerá também na Confessio Gallicana (Artigo 4) de 1559.

19 CALVINO, Institutas, III.1.1.

${ }^{20}$ BÍBLIA SAGRADA. Edição Revista e Atualizada no Brasil de João Ferreira de Almeida. 2. ed. Barueri: Sociedade Bíblica do Brasil, 1993.

${ }^{21}$ CALVINO, João. Comentário ao Evangelho de João. Disponível em: <http://mais.uol.com.br/view/ hqlkba5b6mm0/comentario-de-joao-665-04024D1B326EE4895326?types=A\&>. Acesso em: 01 maio 2017.

22 CALVINO, João. Commentary on Exodus. Harmony of the Law. Disponível em: < https://www.monergism. com/thethreshold/articles/onsite/calvin_exodus.html>. Acesso em: 01 maio 2017.

23 WENDELL, François: Calvin: Origins and Development of His Thought. 2nd edition. Grand Rapids: Eerdmans, 1995. p. 239.

${ }^{24}$ Para detalhes quanto à compreensão de união mística em Calvino, consultar, inter alia, TAN, Seng-Kong. Calvin's Doctrine of our Union with Christ. Disponível em: $<$ http://www.quodlibet.net/articles/tan-union. shtml\#_edn2>. Acesso em: 23 abr. 2017

${ }_{25}$ O teólogo Howard G. Hageman defende que a união mística é a chave hermenêutica para a compreensão da espiritualidade em João Calvino. Para detalhes, consultar HAGEMAN, Howard G. Reformed Spirituality. In: COLLINS, Kenneth J. (Ed.). Exploring Christian Spirituality; An Ecumenical Reader. Grand Rapids: Baker, 2000. p. 143. 
fiéis, servir a Deus no mundo, que Calvino entendia como sendo "um teatro no qual o Senhor exibe diante de nós um surpreendente espetáculo de sua glória"26.

\section{O lugar do Espírito Santo na teologia reformada contemporânea - a pneumatologia escatológica de Hendrikus Berkhof e a pneumatologia integral de Jürgen Moltmann}

Tendo apresentado, ainda que apenas em síntese, a compreensão de Calvino quanto ao papel e ao lugar do Espírito na teologia, é chegado o momento de apresentar, também apenas em síntese, a mesma compreensão em dois teólogos reformados contemporâneos, a saber, o holandês Hendrikus Berkhof e o alemão Jürgen Moltmann.

\section{A pneumatologia escatológica de Hendrikus Berkhof}

Hendrikus Berkhof ${ }^{27}$ (1914-1995), holandês de nascimento, ainda pouco conhecido no Brasil, foi um dos principais teólogos da tradição calvinista do século passado. Foi um teólogo sistemático que aliou os estudos bíblicos e históricos ao processo de construção de seu edifício teológico. Sua teologia enfatizou muito a responsabilidade das implicações sociais e também o aspecto ecumênico da fé cristã, aliando uma articulação entre o conhecimento da ortodoxia cristã clássica e uma visão crítica dessa mesma tradição. Em outras palavras, a teologia de Berkhof pode ser entendida como uma adaptação do famoso lema da Reforma Protestante do século XVI: theologia reformata et semper reformanda est ("a teologia é reformada (e deve) sempre se reformar") ${ }^{28}$.

O tema da pneumatologia é bastante importante na teologia de Berkhof. Em um dos raros - talvez o único - de seus textos disponíveis em português, um número especial da conhecida revista Concilium publicado como coletânea em homenagem ao seu "quase" patrício Edward Schillebeeckx, há um texto de Berkhof tendo por título O Espírito como "Primeiro Sinal" "29. Nesse texto encontra-se o que tão claramente caracteriza o labor teológico de Berkhof, isto é, fazer teologia sistemática ancorada nos estudos bíblicos e na história da doutrina.

Após traçar um panorama da história da pneumatologia na reflexão teológica europeia (protestante e católica) do século XX, com ênfase em Moltmann, Metz e no homenageado, Schillebeeckx, Berkhof apresenta sua própria compreensão do tema, e o faz a partir de um estudo exegético de alguns textos representativos da pneumatolo-

${ }^{26}$ CALVINO, João. Exposição de 1 Coríntios (1.21). São Paulo: Parácletos, 1996. p. 63.

27 Hendrikus Berkhof não deve ser confundido com o teólogo sistemático estadunidense de linha calvinista Louis Berkhof, muito popular no Brasil.

28 A frase original é ecclesia reformata semper reformanda est ("a igreja (é) reformada e deve sempre se reformar"), cunhada pelo teólogo calvinista holandês Gisbertus Voetius (1589-1676; Gisbertus Voetius é a forma latinizada de seu nome holandês, Gijsbert Voet).

${ }_{29}$ Esse número especial de Concilium (n. 99, Nov. 1974) foi publicado no Brasil em forma de livro com o título A experiência do Espírito Santo. Petrópolis: Vozes, 1979. 
gia paulina (2Co 4.7 - 5.10 e $\mathrm{Rm} 8$ ), nos quais o apóstolo se refere ao Espírito como sendo o "primeiro sinal":

Como teólogo protestante, não quero desculpar-me se [...] me volto para a Bíblia, a fim de aí buscar alimento e orientação para levar adiante o tema do empirismo pneumático e da reflexão pneumatológica. Busco-os no sugestivo termo: "primeiro sinal". Aparece três vezes na literatura paulina: em 2 Cor 1,22; 5,5; e Ef 1,14 ${ }^{[30]}$. Em nenhum dos três casos se trata dum contexto claramente ético. Trata-se, cada vez, dum acontecimento indicativo e dum futuro que já agora se desloca para o nosso presente ${ }^{31}$.

Nesse trecho encontra-se in nuce a maneira de Berkhof fazer teologia e sua articulação criativa da pneumatologia, entendida na perspectiva de uma escatologia realizada. Na passagem de 2 Coríntios 4.7 - 5.10, Berkhof destaca que Paulo se dirige aos cristãos coríntios falando dos sofrimentos que estava a enfrentar. Sua práxis ministerial apostólica o conduziu a sofrimento (um contraste tremendo com os lideres religiosos brasileiros contemporâneos que por sua própria conta se autodenominam “apóstolos”), mas nesse contexto de sofrimento o texto menciona a esperança e a ação do Espírito. Motivado pela esperança dada pelo Espírito, o apóstolo prossegue em sua práxis:

O Espírito é a força que faz com que se continue a crer isso no meio dos sofrimentos (v. 13). Oferece, inclusive, um ponto de referência promissor num sinal perceptível: no existir, na construção e no crescimento da comunidade (v. 15). Contudo, não é este visível do presente, e sim o invisível do futuro que é a fonte da qual o Espírito faz jorrar, para os que crêem [sic!], alegria, coragem e renovação (v. 16-18). Graças a essa força do Espírito, Paulo pode suportar a dureza e o absurdo do sofrimento. Pois o Espírito afirma que essa tribulação "prepara” a glória (v. 17), não em virtude dum sentido inerente a ela, de purificação, de mística do sofrimento ou de coisa semelhante, mas porque o Espírito nos torna conforme a Cristo, que, através do caminho de práxis da obediência e por seu subseqüente [sic!] sofrer e morrer, chegou à ressurreição e glorificação [...] O Espírito dá aos nossos corações a antecipação da ressurreição futura. Pela fé já sentimos, agora, algo do gozo da ressurreição. A alegria pelo que há de vir é o antídoto contra o absurdo do sofrimento no tempo presente. É assim que nos encheremos de coragem para aceitar mais uma vez para nós a práxis que conduziu ao sofrimento. Só assim permaneceremos no caminho do futuro (v. $9 \mathrm{~s})^{32}$.

${ }^{30}$ A versão desse texto de Berkhof em português é uma tradução do original holandês. A expressão "primeiro sinal", usada para dar título ao artigo/capítulo, refere-se à palavra grega $\alpha \rho \rho \alpha \beta \omega ́ v$ (arrabon), que nas versões portuguesas da Bíblia tem sido traduzida de diferentes maneiras, porém todas com o mesmo sentido do "primeiro sinal" utilizado por Berkhof: "penhor" (Tradução Brasileira, Almeida Revista e Corrigida, Almeida Revista e Atualizada, Bíblia de Jerusalém, Bíblia do Peregrino), "garantia" (Nova Versão Internacional, Edição Pastoral, Tradução da CNBB, Nova Tradução na Linguagem de Hoje, Almeida Século 21). A versão em português mais "diferente", mas mesmo assim absolutamente fiel ao sentido do "primeiro sinal" enfatizado por Berkhof é $A$ Mensagem: "O Espírito de Deus nos dá uma pitada desse sublime, dando-nos um gostinho do que está por vir".

${ }^{31}$ BERKHOF, Hendrikus. O Espírito como "Primeiro Sinal". In: CONGAR, Yves (Org.). A experiência do Espírito. Petrópolis: Vozes, 1979. p. 158.

32 BERKHOF, 1979, p. 169-170. (ênfases do original). 
A pneumatologia de Berkhof é aqui chamada de "escatológica" exatamente por conta desse aspecto de impulsionar o povo de Deus para o futuro, a despeito do sofrimento presente, dando certeza da filiação divina: "É por isso que gosto da surpreendente implicação que dá o Catecismo de Heidelberg ${ }^{[33]}$ do último artigo do Credo: 'Qual é o consolo que lhe proporciona o artigo acerca da vida eterna? - É o de que, sentindo já agora em meu coração o começo da eterna alegria, após esta vida possuirei de forma plena a felicidade futura" 34 .

Em suma: Berkhof constrói sua pneumatologia de maneira muito criativa, aliando os estudos bíblicos à sua própria tradição eclesiástica e teológica. A articulação entre pneumatologia e escatologia oferece possibilidades de aplicação pastoral e missiológica, pois para o teólogo holandês o Espírito antecipa o futuro e confirma no coração dos cristãos a força para o testemunho de Cristo no mundo, mesmo em meio a sofrimento. Assim, em linhas gerais, Berkhof é fiel à compreensão pneumatológica de Calvino, enquanto, ao mesmo tempo, apresenta sua própria elaboração a respeito.

\section{A pneumatologia integral de Jürgen Moltmann ${ }^{35}$}

Jürgen Moltmann (n. 1926) é um dos principais teólogos em atividade no mundo. Dificilmente se poderá exagerar o alcance e o impacto da teologia de Moltmann na reflexão teológica desde a década de 60 do século passado, tanto em círculos protestantes, aos quais ele está afiliado, como também em católicos e ortodoxos orientais. Sua obra é vasta, e cobre vários capítulos da teologia sistemática. Moltmann tem realizado um diálogo profícuo com a tradição da teologia latino-americana. Alguns de seus textos, como Theologie der Hoffnung ("Teologia da esperança") ${ }^{36}$, publicado originalmente em 1964, na qual dialoga com Das Prinzip Hoffnung ("O princípio esperança") do filósofo marxista Ernst Bloch, e Der Gekreuzigte Gott ("O Deus crucificado")), de 1972, no qual resgata o tema da theologia crucis ("teologia da cruz") de Lutero e faz um esforço para fazer teologia depois de Auschwitz, tornaram-se clássicos da literatura teológica mundial.

Conforme mencionado, Moltmann tem produzido uma reflexão sobre diferentes tópicos da teologia sistemática, o que inclui a pneumatologia. Em Kirche in

\footnotetext{
33 O Catecismo de Heidelberg é um dos símbolos de fé da Igreja Reformada Holandesa, da qual Berkhof era membro. Foi formulado em 1563 pelos teólogos Gaspar Olevianus e Zacharias Ursinus, de orientação calvinista. O catecismo apresenta 129 perguntas e respostas para serem recitadas ao longo dos 52 domingos do ano, cobrindo os seguintes temas: criação, o pecado humano, a salvação, a gratidão pela salvação, a Palavra e os sacramentos (Batismo e Ceia/Eucaristia), e uma explicação da oração do Pai-Nosso e dos Dez Mandamentos. A pergunta e a resposta às quais Berkhof faz menção em seu texto é a 58, do Domingo 22. Para o texto completo do Catecismo de Heidelberg em português, consultar: $<$ http://www.monergismo. com/textos/catecismos/catecismo_heidelberg.htm>. Acesso em: 30 abr. 2017

34 BERKHOF, 1979, p. 174.

35 Essa subseção do presente texto é extraída do próprio subtítulo de um dos trabalhos de Moltmann sobre o tema pneumatológico: Der Geist des Lebens - Eine Ganzheitliche Pneumatologie, de 1991. Edição brasileira: O Espírito da vida. Uma pneumatologia integral. Petrópolis: Vozes, 1999.

${ }^{36}$ MOLTMANN, Jürgen. Teologia da esperança. São Paulo: Teológica, 2004.

37 MOLTMANN, Jürgen. O Deus crucificado. Santo André: Academia Cristã, 2011a.
} 
der Kraft des Geistes ("Igreja no poder do Espírito", 1975) Moltmann constrói uma eclesiologia em perspectiva pneumatológica, enfatizando o papel do Espírito como motivador da igreja em missão no mundo. ${ }^{38}$ Em Trinität und Reich Gottes ("Trindade e Reino de Deus", 1980) Moltmann trata do complexo tema da Trindade, nos aspectos conhecidos na teologia clássica como Trindade Ontológica e Trindade Econômica. ${ }^{39}$ Moltmann voltará sua atenção ao tema do Espírito em Die Quelle des Lebens - Der Heilige Geist und die Theologie des Lebens ("A fonte da vida - O Espírito Santo e a teologia da vida", 1997). Tal como sugerido pelo próprio título do livro, o "ponto" da abordagem de Moltmann é o papel do Espírito na dinâmica da existência, como elo de comunhão entre as pessoas e Deus, entre as pessoas umas com as outras e entre as pessoas com a criação:

No sentido originário e perene, a missão é missio Dei [missão de Deus][...] Missio Dei nada mais é que o envio do Espírito Santo do Pai por intermédio do Filho a este mundo para que este mundo não se arruíne, mas viva[...] Pois o Espírito Santo é a "Fonte da vida", trazendo vida para dentro do mundo: vida total, vida plena, irrestrita, indestrutível, vida eterna ${ }^{40}$.

A pneumatologia de Moltmann pode, de fato, sem exagero, ser considerada como integral, porque articula a Trindade em seus inter-relacionamentos íntimos internos eternos, marcados pelo amor - a Trindade Imanente, ou Ontológica - e com o mundo, também marcados pelo amor, e caracterizados especificamente pela ação salvífica, com a igreja em missão e com o todo da criação - a Trindade Econômica. Um resumo útil de como o tema pneumatológico perpassa a reflexão teológica de Moltmann é apresentado por Josias da Costa Junior, da seguinte maneira:

Nessas obras Moltmann revela que o Espírito Santo está em comunhão trinitária com o Pai e o Filho (Trindade e Reino de Deus); ele é a força vital da criação (Deus na criação); ele também é aquele que dá vida a Jesus e é a força da sua ressurreição (O caminho de Jesus Cristo); além disso, o Espírito é também a vitalização e a santificação da vida (O Espírito da vida $)^{41}$.

Logo, a pneumatologia moltmanniana enfatiza a liberdade absoluta do Espírito (conforme a metáfora jesuânica do vento em João 3). A tendência evangélica em geral é pensar a ação do Espírito em termos puramente individualistas e soteriológicos. Moltmann, com sua pneumatologia integral, resgata a ênfase bíblica da ação cósmica

38 MOLTMANN, Jürgen. A igreja no poder do Espírito. Santo André: Academia Cristã, 2013.

39 MOLTMANN, Jürgen. Trindade e Reino de Deus. Uma contribuição para a teologia. 2. ed. Petrópolis: Vozes, $2011 \mathrm{~b}$.

${ }^{40}$ MOLTMANN, Jürgen. O espírito da vida. Uma pneumatologia integral. Petrópolis: Vozes, 1999. p. 17. (ênfases do original).

${ }^{41}$ COSTA JÚNIOR, Josias da. O Espírito criador. A ecologia na teologia trinitária de Jürgen Moltmann. 2008. Tese de Doutorado (Teologia) - PUC Rio, Rio de Janeiro, 2008. p. 127. 
do Espírito, que não se restringe de modo algum à salvação de indivíduos. ${ }^{42} \mathrm{Sem}$ negar essa particularidade da obra do Espírito, em muito a ultrapassa. Em outras palavras: Moltmann não nega a ação soteriológica do Espírito, antes acrescenta a dimensão das ações do Espírito da vida que, enviado pelo Pai, renova a face da terra (cf. Sl 104.30). Tal ênfase na ação cósmica do Espírito tem implicações éticas óbvias e mais que necessárias em tempo tal como o atual, em que nunca o meio ambiente esteve tão ameaçado como atualmente. Nas palavras de Moltmann:

Confrontados com o "fim da natureza", ou as igrejas irão descobrir a importância cósmica de Cristo e do Espírito, ou elas se tornarão cúmplices no aniquilamento da criação de Deus aqui na terra [...] A descoberta da amplitude cósmica do Espírito de Deus, ao invés, leva a respeitar a dignidade de todas as criaturas, nas quais Deus está presente por seu Espírito. Na situação atual, esta descoberta não é poesia romântica, nem visão especulativa, mas sim a condição necessária para a sobrevivência da humanidade nesta terra de Deus, que é única ${ }^{43}$.

Certamente há muitas outras possibilidades de "aplicação" da dimensão cósmica da dinâmica do Espírito. Poder-se-ia, a partir dessa mencionada dimensão cósmica, pensar na pneumatologia como base teórica para uma teologia pública. Há outros possíveis desdobramentos. São possibilidades para futuras reflexões a respeito desse tema instigante.

\section{Considerações finais - A era do Espírito}

Concluindo, não custa repetir a primeira afirmação deste texto, qual seja, que o propósito deste artigo, em consonância com o painel que o motivou, é apresentar, posto que em síntese, a visão da teologia reformada quanto ao tema pneumatológico. Tentando ser coerente com essa proposta, não foram apresentadas em detalhes as ênfases evangélica e a pentecostal quanto a esse tema. Cada um desses dois possíveis temas permite falar muito a respeito. Todavia, o que foi exposto, espero, é suficiente para o início de uma reflexão sobre o papel do Espírito na tradição da teologia reformada em diálogo com as tradições católica e luterana, como é o propósito deste painel.

A importância desse "triálogo" sobre o tema pneumatológico está no fato que uma (re)descoberta e (re)valorização da compreensão cristã da ação do Espírito têm grande potencial para uma revitalização e oxigenação da missão da ecumene do povo de Deus no mundo. Uma saudável teologia do Espírito deverá incluir elementos advindos das compreensões pneumatológicas católica, luterana e reformada. Nenhuma dessas três será capaz de abarcar em profundidade ou extensão toda a amplitude e riqueza do ensino escriturístico e também da tradição cristã sobre esse tema. E mesmo uma pneumatologia que reúna colaborações dessas três tradições não será completa,

\footnotetext{
${ }^{42}$ Cf. MOLTMANN, Jürgen. A fonte da vida - O Espírito Santo e a teologia da vida. São Paulo Loyola, 2002. p. 21.

43 MOLTMANN, 2002, p. 22 (ênfases do autor).
} 
visto que o todo é maior que a soma de suas partes. Mas uma abordagem ecumênica dessa natureza será um bom começo para uma compreensão mais ampla da pessoa e da obra do Espírito, no cosmo, na história e nas igrejas.

A tradição reformada, que se constitui no foco propriamente da presente reflexão, enfatiza o papel do Espírito como assegurando aos cristãos a convicção de que são filhos e filhas de Deus, seguindo-se daí como consequência um fortalecimento para sua ação no mundo como seguidores e seguidoras de Jesus de Nazaré. As tradições luterana e católica têm suas próprias ênfases sobre a pessoa e a obra do Espírito no mundo. O que importa é buscar convergências nessas compreensões sem negligenciar as diferenças, mas acima de tudo que todos se lembrem da recomendação paulina de "não apagar o Espírito" (1Ts 5.19).

\section{Referências}

ABEL, Jean. The ethical implications of the doctrine of the Holy Spirit in John Calvin. 1948. Master Thesis (Theology) - Union Theological Seminary, Richmond, 1948.

BEINTKER, Michael. Calvins Theologie des Heiligen Geistes. Disponível em: <http://www. reformiert-info.de/daten/File/Upload/doc-2435-1.pdf>. Acesso em: 03 abr. 2017.

BENNETT, Charles Oliver. John Calvin: his teaching on the Holy Scriptures: a study on the necessity of the Scriptures in the Holy Spirit's effectual call of the saints. 1951. Master Thesis (Theology) - New Brunswick Theological Seminary, New Brunswick, 1951.

BERKHOF, Hendrikus. O Espírito Santo como 'Primeiro Sinal'. In: CONGAR, Yves (Org.) A experiência do Espírito. Petrópolis: Vozes, 1979.

BETTENSON, Harry. Documentos da igreja cristã. São Paulo: ASTE, 1967.

BÍBLIA SAGRADA. Edição Revista e Atualizada no Brasil de João Ferreira de Almeida. 2. ed. Barueri: Sociedade Bíblica do Brasil, 1993

CALVINO, João. As Institutas ou Tratado da Religião Cristã. Livros I, II, III e IV. São Paulo: Casa Editora Presbiteriana, 1985, 1989.

. Exposição de 1 Coríntios. São Paulo: Parácletos, 1996.

. Comentário ao Evangelho de João. Disponível em: <http://mais.uol.com.br/view/ hqlkba5b6mm0/comentario-de-joao-665-04024D1B326EE4895326?types=A\&>. Acesso em: 01 maio 2017.

. Commentary on Exodus. Harmony of the Law. Disponível em: $<$ https://www.monergism. com/thethreshold/articles/onsite/calvin_exodus.html>. Acesso em: 01 maio 2017.

CATECISMO DE HEIDELBERG. Disponível em: < http://www.monergismo.com/textos/catecismos/catecismo_heidelberg.htm>. Acesso em: 30 abr. 2017.

COSTA JÚNIOR, Josias da. O Espírito criador. A ecologia na teologia trinitária de Jürgen Moltmann. 2008. Tese de Doutorado (Teologia) - PUC Rio, Rio de Janeiro, 2008. p. 127.

EDWARDS, Jonathan. A verdadeira obra do Espírito. Sinais de autenticidade. São Paulo: Vida Nova, 1992.

HAGEMAN, Howard G. Reformed Spirituality. In: COLLINS, Kenneth J. (ed.). Exploring Christian Spirituality; An Ecumenical Reader. Grand Rapids: Baker, 2000.

KIDD, Thomas. The Great Awakening: Evangelical Roots of Christianity in America. Yale: Yale University Press, 2007.

MARSDEN, George. The Evangelical Mind and the New School Presbyterian Experience: A Case Study of Thought and Theology in Nineteenth-Century America. Eugene: Wipf \& Stock, 2003. MOLTMANN, Jürgen. O Espirito da vida. Uma pneumatologia integral. Petrópolis: Vozes, 1999. 
MOLTMANN, Jürgen. A fonte da vida - O Espírito Santo e a teologia da vida. São Paulo Loyola, 2002.

Teologia da esperança. São Paulo: Teológica, 2004.

O Deus crucificado. Santo André: Academia Cristã, 2011a.

$2011 b$.

Trindade e Reino de Deus. Uma contribuição para a teologia. 2. ed. Petrópolis: Vozes,

Igreja no poder do Espírito. Uma contribuição a uma eclesiologia messiânica. Santo André: Academia Cristã, 2013.

MORII, Makoto. La notion du Saint-Esprit chez Calvin dans son development historique. 1961. Thése de maîtrise (Théologie) - Faculté de Théologie Protestante de Strasbourg, Strasbourg, 1961. OWEN, John. Pneumatologia: A Discourse Concerning the Holy Spirit. [s.1.]: Create Space Independent Publishing Platform, 2015. 2 v.

O'BRIEN, Henry. The Holy Spirit in the catechetical writings of John Calvin: a comparative study with other contemporary presentations of Christian doctrine between 1529 and 1566 . 1991. Doctoral dissertation (Theology) -Pontificia Universitas Gregoriana, Facultas Theologiae, Vaticano, 1991.

PEW RESEARCH CENTER - RELIGION AND PUBLIC LIFE. Global Christianity - A Report on the Size and Distribution of World's Christian Population. Disponível em: <http://www. pewforum.org/2011/12/19/global-christianity-exec/>.

QUISTORP, Heinrich J. J. Th. Calvins Lehre vom Heiligen Geist. In: VRIEZEN, Theodorus Christiaan. De Spiritu Sancto. Bijdragen tot de leer van de Heilige Geest bij gelegenheid van het 2e eeuwfeest van het Stipendium Bernardinum. Utrecht: Kemifik, 1964.

TAN, Seng-Kong. Calvin's Doctrine of our Union with Christ. Disponível em: <http://www. quodlibet.net/articles/tan-union.shtml\#_edn2>. Acesso em: 01 maio 2017.

VAN`T SPIJKER, W. Die Lehre vom Heiligen Geist bei Bucer und Calvin. In: NEUSER, Wilhem H. (Ed.). Calvinus Servus Christi. Die Referate des Internationalen Kongresses für Calvinforschung, Debrecen, 1986. Budapest: Presseabteilung des Raday-Kollegiums, 1988.

VENI CREATOR SPIRITUS. Oração ao Espírito Santo. Disponível em: $<$ http://www.comshalom. org/oracao-ao-espirito-santo-veni-creator-spiritus/>. Acesso em: 01 maio 2017.

WALTERS, Gwyn. The Doctrine of the Holy Spirit in John Calvin. 1949. Ph. D. Thesis (Theology) - University of Edinburgh, Edinburgh, 1949.

WARFIELD, Benjamin B. Calvin and Augustine. Philipsburg: Presbyterian and Reformed, 1956. WENDELL, François. Calvin: Origins and Development of His Thought. 2. ed. Grand Rapids: Eerdmans, 1995.

ZERWAS, Jack La-Vere. The Holy Spirit in Calvin. 1947. Master Thesis (Theology) - Union Theological Seminary, New York, 1947. 